\title{
Calcium sparks in the intact gerbil spiral modiolar artery
}

Gayathri Krishnamoorthy ${ }^{1}$, Keil Regehr ${ }^{1,3}$, Samantha Berge ${ }^{1}$, Elias Q Scherer ${ }^{2}$ and Philine Wangemann ${ }^{1^{*}}$

\begin{abstract}
Background: Calcium sparks are ryanodine receptor mediated transient calcium signals that have been shown to hyperpolarize the membrane potential by activating large conductance calcium activated potassium (BK) channels in vascular smooth muscle cells. Along with voltage-dependent calcium channels, they form a signaling unit that has a vasodilatory influence on vascular diameter and regulation of myogenic tone. The existence and role of calcium sparks has hitherto been unexplored in the spiral modiolar artery, the end artery that controls blood flow to the cochlea. The goal of the present study was to determine the presence and properties of calcium sparks in the intact gerbil spiral modiolar artery.

Results: Calcium sparks were recorded from smooth muscle cells of intact arteries loaded with fluo-4 AM. Calcium sparks occurred with a frequency of $2.6 \mathrm{~Hz}$, a rise time of $17 \mathrm{~ms}$ and a time to half-decay of $20 \mathrm{~ms}$. Ryanodine reduced spark frequency within $3 \mathrm{~min}$ from 2.6 to $0.6 \mathrm{~Hz}$. Caffeine $(1 \mathrm{mM})$ increased spark frequency from 2.3 to $3.3 \mathrm{~Hz}$ and prolonged rise and half-decay times from 17 to $19 \mathrm{~ms}$ and from 20 to $23 \mathrm{~ms}$, respectively. Elevation of potassium (3.6 to $37.5 \mathrm{mM}$ ), presumably via depolarization, increased spark frequency from 2.4 to $3.2 \mathrm{~Hz}$. Neither ryanodine nor depolarization changed rise or decay times.

Conclusions: This is the first characterization of calcium sparks in smooth muscle cells of the spiral modiolar artery. The results suggest that calcium sparks may regulate the diameter of the spiral modiolar artery and cochlear blood flow.
\end{abstract}

\section{Background}

The gerbil spiral modiolar artery (SMA) originates via the anterior inferior cerebellar artery from the basilar artery and provides the blood supply to the cochlea. It has an outer diameter of $\sim 60 \mu \mathrm{m}$ and follows the eighth cranial nerve from the brain stem to the modiolus of the cochlea [1]. The SMA is an end-artery that feeds the capillary networks of the spiral ligament and the stria vascularis, which maintains the endocochlear potential essential for hearing [2]. This energy-intensive mechanism renders the cochlea vulnerable to ischemia, which is thought to be involved in the pathogenesis of hearing loss and tinnitus. Consequently, the mechanisms that regulate the diameter of the SMA and thereby cochlear blood flow are of great interest.

Vascular tone is determined by the contractility of the smooth muscle cell, which is regulated by membrane-

\footnotetext{
* Correspondence: wange@vet.ksu.edu

'Anatomy \& Physiology Department, Kansas State University, Manhattan, Kansas 66506, USA

Full list of author information is available at the end of the article
}

potential and $\mathrm{Ca}^{2+}$-dependent as well as independent mechanisms [3]. An important regulator of smooth muscle contractility is the ryanodine receptor (RyR) mediated " $\mathrm{Ca}^{2+}$ spark". $\mathrm{Ca}^{2+}$ sparks are the physical manifestation of coordinated openings of clustered RyRs causing a highly localized and transient increase in the $\mathrm{Ca}^{2+}$ concentration in the subsarcolemmal space [4]. $\mathrm{Ca}^{2+}$ sparks have been demonstrated in all muscle cells - cardiac, skeletal as well as smooth muscle cells. In cardiac and skeletal muscle cells, tight coupling between sarcolemmal voltage-dependent $\mathrm{Ca}^{2+}$ channels (VDCCs) in the T-tubules and RyRs in the terminal cisternae generates a depolarization-induced $\mathrm{Ca}^{2+}$-induced-Ca ${ }^{2+}$-release (CICR) process that causes contraction [4]. On the other hand, in smooth muscle cells, particularly in vascular smooth muscle cells, RyRs, large-conductance calcium- and voltage-activated $\mathrm{K}^{+}(\mathrm{BK})$ channels and VDCCs have been shown to form a functional triad that maintains or mediates vasodilation by limiting $\mathrm{Ca}^{2+}$ influx via VDCCs [5-8]. Increases in the $\mathrm{Ca}^{2+}$ concentration in the subsarcolemmal space caused by $\mathrm{Ca}^{2+}$ sparks, which engulf the cytosolic face of BK 
channels, cause activation of these channels and hyperpolarization of the membrane potential, closure of VDCCs and vasodilation via a decrease in the cytosolic $\mathrm{Ca}^{2+}$ concentration in the vicinity of the contractile myofilaments. Thus, $\mathrm{Ca}^{2+}$ sparks form a negative feedback mechanism that regulates vascular tone and hence blood flow. This mechanism has not yet been identified in the regulation of cochlear blood flow. Previous studies from our lab have indicated the presence of a ryanodine-sensitive $\mathrm{Ca}^{2+}$ sensing receptor in vascular smooth muscle cells that regulates the contractility of the gerbil SMA [9]. A role for RyR-mediated $\mathrm{Ca}^{2+}$ release in hyperpolarization of smooth muscle cells, mediated by activation of BK channels, has been previously suggested in guinea-pig SMA [10].

The goal of the present study was to detail the presence and properties of $\mathrm{Ca}^{2+}$ sparks in smooth muscle cells of the intact gerbil spiral modiolar artery. To that end, a protocol for the measurement of $\mathrm{Ca}^{2+}$ sparks in the gerbil SMA was established and software for the analysis of $\mathrm{Ca}^{2+}$ sparks was developed. We demonstrate for the first time, a detailed analysis of the kinetics and properties of $\mathrm{Ca}^{2+}$ sparks in smooth muscle cells of the intact gerbil SMA and their regulation by pharmacological activators and inhibitors of RyRs as well as changes in smooth muscle membrane potential. The data suggest that $\mathrm{Ca}^{2+}$ sparks are important for regulating the contractility of the smooth muscles of the SMA and thereby vascular tone and cochlear blood flow.

\section{Results}

\section{Localization of ryanodine receptors}

In the first series of experiments, ryanodine receptors were visualized using a green fluorescent derivative of ryanodine. A punctuate staining pattern was expected if ryanodine receptors were limited to or concentrated at distinct spark sites. Staining with $1 \mu \mathrm{M}$ Bodipy ${ }^{\circledR}$ FL-X ryanodine produced a pattern that was consistent with RyRs being uniformly expressed in the sarcoplasmic reticulum (Figure 1). Specificity of staining was verified by competition with unlabeled ryanodine. Nearly no staining was observed with $1 \mu \mathrm{M}$ Bodipy ${ }^{\circledR} \mathrm{FL}-\mathrm{X}$ ryanodine in the presence of $250 \mu \mathrm{M}$ unlabelled ryanodine. No evidence for a concentration of ryanodine receptors to distinct spark sites was obtained. The staining pattern is consistent with the theory of loose coupling between plasmalemmal L-type $\mathrm{Ca}^{2+}$ channels and sarcoplasmic RyRs in smooth muscle as against the direct spatial and physical coupling observed in cardiac and skeletal muscle respectively [11].

\section{Detection of $\mathrm{Ca}^{2+}$ sparks}

In a typical recording of $\mathrm{Ca}^{2+}$ sparks from a smooth muscle cell of the intact SMA loaded with the $\mathrm{Ca}^{2+}$ indicator fluo-4, $\mathrm{Ca}^{2+}$ sparks occurred spontaneously

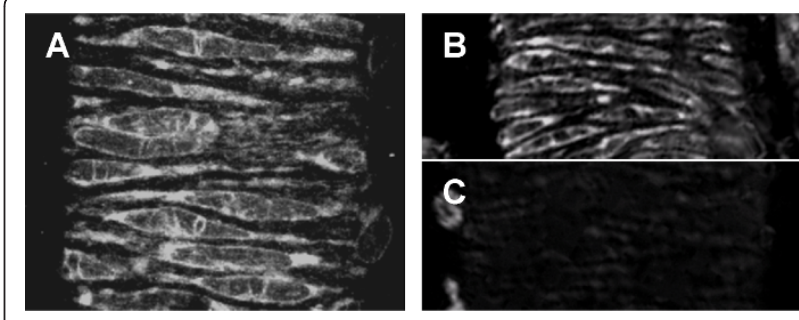

Figure 1 Staining for ryanodine receptors in the spiral modiolar artery. (A) Ryanodine receptors were labeled with $1 \mu \mathrm{M}$ Bodipy ${ }^{\mathbb{B}}$-ryanodine. Specificity was evaluated by staining with $1 \mu \mathrm{M}$ Bodipy ${ }^{\mathbb{B}}$-ryanodine in the absence (B) or presence (C) of $250 \mu \mathrm{M}$ unlabelled ryanodine.

(Figure 2). Representative image frames recorded at 41.5 $\mathrm{ms}$ intervals show a $\mathrm{Ca}^{2+}$ spark occurring at $124.5 \mathrm{~ms}$ after the start of recording (frame 3 of Figure 2A), that rapidly decayed within a single frame interval of $41.5 \mathrm{~ms}$ (frame 4). $\mathrm{Ca}^{2+}$ sparks occupied a mean spatial width of $2.4 \pm 0.1 \mu \mathrm{m}(\mathrm{n}=25$ spark sites). For further analysis of sparks, nine consecutive line-scans, each lasting $5 \mathrm{~s}$ with a 20 s interval between scans, were recorded at selected spark sites. There was no loss of fidelity in the observed $\mathrm{Ca}^{2+}$ sparks under control conditions for the duration of the nine line-scans. Figure 2B shows a typical $5 \mathrm{~s}$ line scan recording of a chosen spark site where robust $\mathrm{Ca}^{2+}$ sparks occurred with high frequency. Custom written software described in methods proved very effective in detecting and analyzing $\mathrm{Ca}^{2+}$ sparks and spark kinetics from line scans (Figure 2C and 2D). Spark parameters were averaged over the entire recording period. In this preparation under control conditions, $\mathrm{Ca}^{2+}$ sparks occurred with a frequency of $2.6 \pm 0.1 \mathrm{~Hz} /$ spark site (n $=105$ spark sites), with a rise time of $17 \pm 0.3 \mathrm{~ms}$ and a time to half decay of $21 \pm 0.7 \mathrm{~ms}$ (averaged from 4,103 sparks recorded from 105 spark sites).

\section{Effect of ryanodine and caffeine on $\mathrm{Ca}^{2+}$ sparks}

Ryanodine is a plant alkaloid that specifically binds to RyRs and inhibits them at micromolar concentration, leading to the cessation of $\mathrm{Ca}^{2+}$ sparks. A typical linescan experiment for the application of ryanodine is depicted in Figure 3A. $1 \mu \mathrm{M}$ ryanodine caused a significant decrease in $\mathrm{Ca}^{2+}$ spark frequency and amplitude by scan 9 (Figure 3B). In five experiments, there was complete cessation of sparks before the end of the experiment. $\mathrm{Ca}^{2+}$ spark frequency in the presence of ryanodine, averaged from 11 experiments, was $0.6 \pm 0.3$ $\mathrm{Hz} / \mathrm{spark}$ site, which is a $\sim 4$-fold decrease to that observed without ryanodine (Figure 3C). Interestingly, ryanodine did not have a significant effect on the risetime or decay time of sparks. Rise time and decay time were $17 \pm 1 \mathrm{~ms}$ and $14 \pm 2 \mathrm{~ms}$ respectively in the presence of ryanodine (averaged from 104 sparks recorded 


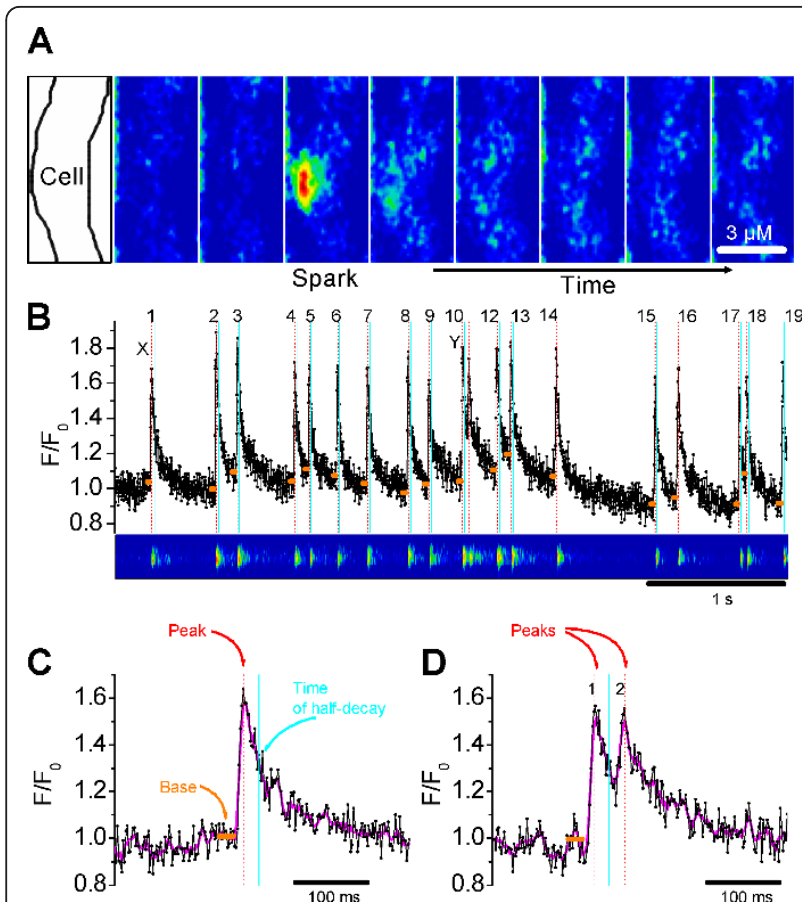

Figure 2 Imaging and recording of $\mathrm{Ca}^{2+}$ sparks. (A) Series of confocal images obtained at a temporal resolution of $41.5 \mathrm{~ms}$. $\mathrm{Ca}^{2+}$ sparks were identified as highly localized elevations in the cytosolic $\mathrm{Ca}^{2+}$ concentration of the smooth muscle cell (outlined in the leftmost image).(B) Image and fluorescent trace obtained from a typical $5 \mathrm{~s}$ scan at a temporal resolution of $1.92 \mathrm{~ms}$ shows spontaneous $\mathrm{Ca}^{2+}$ sparks occurring with high frequency. Numbers beside transients indicate sparks. Sparks were identified and frequency was calculated using custom-designed software. The sparks marked ' $x$ ' and ' $y$ ' are shown in (C) and (D) with an expanded resolution. Amplitude (Peak - Base intensity), rise time (Peak - Base time) and time to half decay (Half decay - Peak time) were obtained from individual $\mathrm{Ca}^{2+}$ sparks. (C) An example showing identification of sparks and calculation of spark parameters by the software for a $\mathrm{Ca}^{2+}$ spark rising from the baseline. (D) An example showing identification of sparks and calculation of spark parameters by the software for a $\mathrm{Ca}^{2+}$ spark "pair", where the second spark rises before the first returns to baseline. Spark amplitude, rise time and decay time are calculated only from the first and not the second spark.

from 8 spark sites) and $18 \pm 0.6 \mathrm{~ms}$ and $21 \pm 3 \mathrm{~ms}$ respectively in time-matched controls.

Caffeine is an activator of RyRs, which at very low concentrations $(\mu \mathrm{M}-1 \mathrm{mM})$ causes an increase in spark frequency whereas when used in high concentrations $(>5$ $\mathrm{mM}$ ) induces a robust $\mathrm{Ca}^{2+}$ release that depletes the $\mathrm{Ca}^{2+}$ stores [4]. Consistent with previous reports of the effects of low concentrations of caffeine, $1 \mathrm{mM}$ caffeine induced significant reversible increases in $\mathrm{Ca}^{2+}$ spark frequency, rise time and time to half-decay in the smooth muscle cells of the SMA (Figure 4). Spark frequency was $3.3 \pm$ $0.4 \mathrm{~Hz} /$ spark site in caffeine vs. $2.3 \pm 0.2 \mathrm{~Hz} /$ spark site in time-matched controls without caffeine $(\mathrm{n}=25)$. Rise
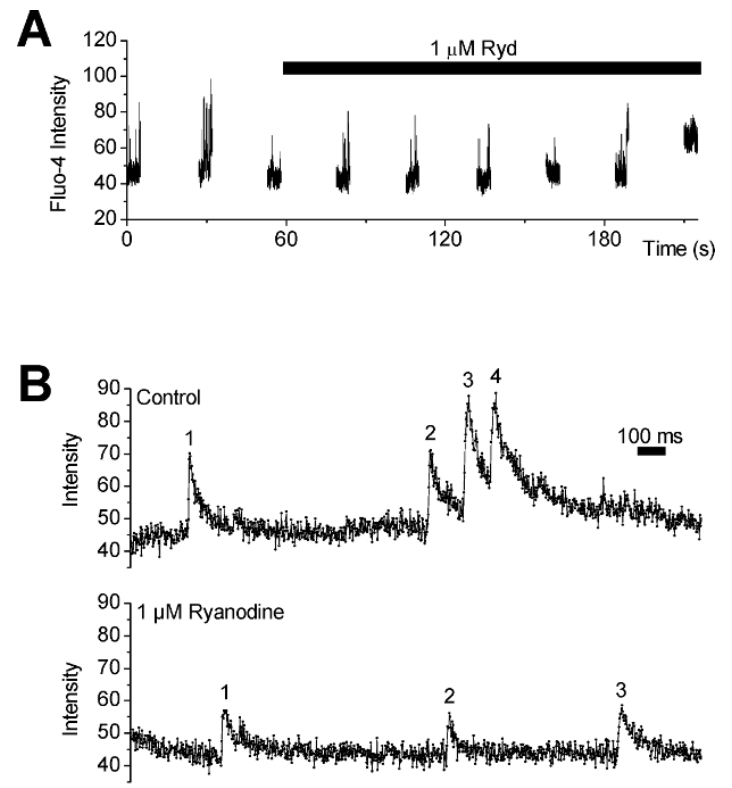

C
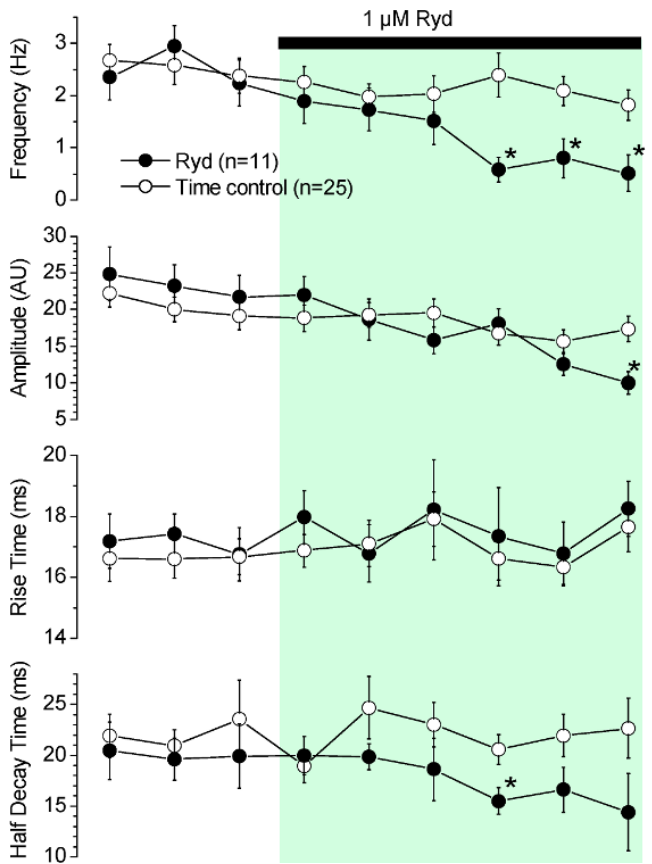

Figure 3 Ryanodine reduces the frequency of $\mathrm{Ca}^{2+}$ sparks. (A) A typical experiment for the effects of ryanodine on sparks. Ryanodine decreased spark frequency by the $9^{\text {th }}$ scan. (B) Expanded line scans from (A) shows a trace in control (scan 1) and in ryanodine (scan 9). Numbers beside transients indicate sparks. (C) Ryanodine reduced the frequency of $\mathrm{Ca}^{2+}$ sparks but had no major effect on $\mathrm{Ca}^{2+}$ spark rise time or time to half-decay. Recordings in the presence of ryanodine were made at 10, 40, 70, 100, 130 and 160 s after application of ryanodine. Time control experiments revealed that $\mathrm{Ca}^{2+}$ spark frequency, amplitude, rise time and time to half-decay were reasonably stable for nine $5 \mathrm{~s}$ line scans spread over 225s 


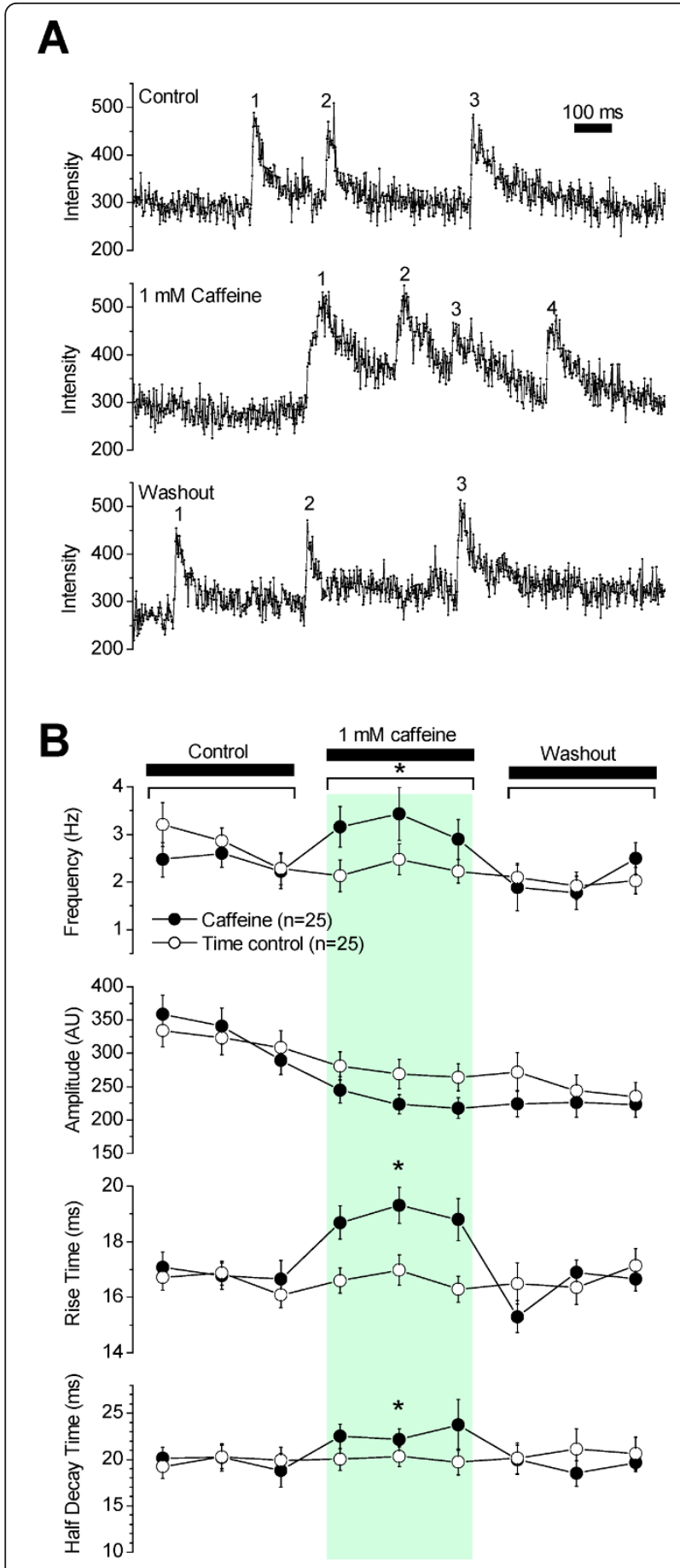

Figure 4 Caffeine altered frequency, rise and decay times of $\mathrm{Ca}^{2+}$ sparks. (A) Original recordings of $\mathrm{Ca}^{2+}$ sparks in the absence (top trace), presence (middle trace) and washout (bottom trace) of $1 \mathrm{mM}$ caffeine. Numbers beside transients indicate sparks. (B) Caffeine increased the frequency, rise and decay time of $\mathrm{Ca}^{2+}$ sparks but had no effect on $\mathrm{Ca}^{2+}$ spark amplitude. Recordings in the presence of caffeine were made at 10,40 and 70s after drug application and recordings during washout were made at 10,40 and 70s after termination of drug application. Time control experiments revealed that $\mathrm{Ca}^{2+}$ spark frequency, amplitude, rise time and time to half-decay were reasonably stable for nine $5 \mathrm{~s}$ line scans spread over $225 \mathrm{~s}$. time was $19 \pm 0.5 \mathrm{~ms}$ (1186 sparks from $\mathrm{n}=25$ sites $)$ in caffeine vs. $17 \pm 0.3 \mathrm{~ms}$ (1618 sparks from $\mathrm{n}=25$ sites $)$ in time-matched controls. Time to half-decay was $23 \pm 1 \mathrm{~ms}$ (1186 sparks from $\mathrm{n}=25$ sites) in caffeine vs. $20 \pm 1 \mathrm{~ms}$ (1618 sparks from $\mathrm{n}=25$ sites) in time-matched controls. In addition to measured spark attributes, spark morphology was altered significantly (Figure 4A). In the presence of caffeine, many sparks exhibited a slower, more rounded rise that lingered at the peak longer than normal sparks, suggesting altered kinetics of RyRs due to activation by caffeine.

\section{Effect of membrane potential depolarization on $\mathrm{Ca}^{2+}$ sparks}

Membrane potential depolarization increases intracellular $\mathrm{Ca}^{2+}$ which in turn increases $\mathrm{Ca}^{2+}$ spark frequency in vascular smooth muscle cells [11-13]. Intact SMA segments were depolarized with a $37.5 \mathrm{mM}\left[\mathrm{K}^{+}\right]$superfusing solution. Consistent with observations in other vascular smooth muscle cells, high $\mathrm{K}^{+}$significantly increased $\mathrm{Ca}^{2+}$ spark frequency in smooth muscle cells of the SMA that returned to control levels upon re-perfusion with PSS (Figure 5A). Spark frequency in high $\mathrm{K}^{+}$was $3.2 \pm 0.3 \mathrm{~Hz} /$ spark site ( $\mathrm{n}=21$ experiments), a 1.4 - fold increase in frequency, with no significant change in spark amplitude, rise time or time to half-decay (Figure 5B).

\section{Discussion and Conclusion}

The SMA, a coiled artery inside the cochlea, is a branch of the anterior inferior cerebellar artery, which in turn branches off from the basilar artery located on the surface of the brain stem [1]. The SMA is a small-caliber vessel (diameter $\sim 60 \mu \mathrm{m}$ ) and has a single layer of smooth muscle cells that lacks tightly attached connective tissue [14]. This architecture makes the SMA exquisitely suitable for investigating smooth muscle cell calcium regulation in small vessels $(<70 \mu \mathrm{m})$ using intact arteries, as opposed to isolated cells, which are devoid of their natural milieu. The major findings of this study using an intact vessel preparation of the SMA are as follows: (1) The SMA contains ryanodine receptors (RyRs) in the smooth muscle cells. (2) Smooth muscle cells of the SMA exhibit $\mathrm{Ca}^{2+}$ sparks, which are inhibited by ryanodine, an inhibitor of RyR. (3) Elevation of $\mathrm{K}^{+}$and caffeine increased the frequency of $\mathrm{Ca}^{2+}$ sparks. The kinetics (rise time, decay time and amplitude) were not affected by $\mathrm{K}^{+}$but were altered by caffeine. These results suggest that RyR-mediated $\mathrm{Ca}^{2+}$ sparks regulate smooth muscle contractility and play a role in the regulation of cochlear blood flow.

$\mathrm{Ca}^{2+}$ sparks, along with BK channel and $\mathrm{Ca}^{2+}$ channel currents play a prominent role in regulating myogenic tone of extra-cerebral arteries on the surface of the brain $[5,8] . \mathrm{Ca}^{2+}$ sparks have been identified in many smooth muscle cells including smooth muscle cells from arteries 


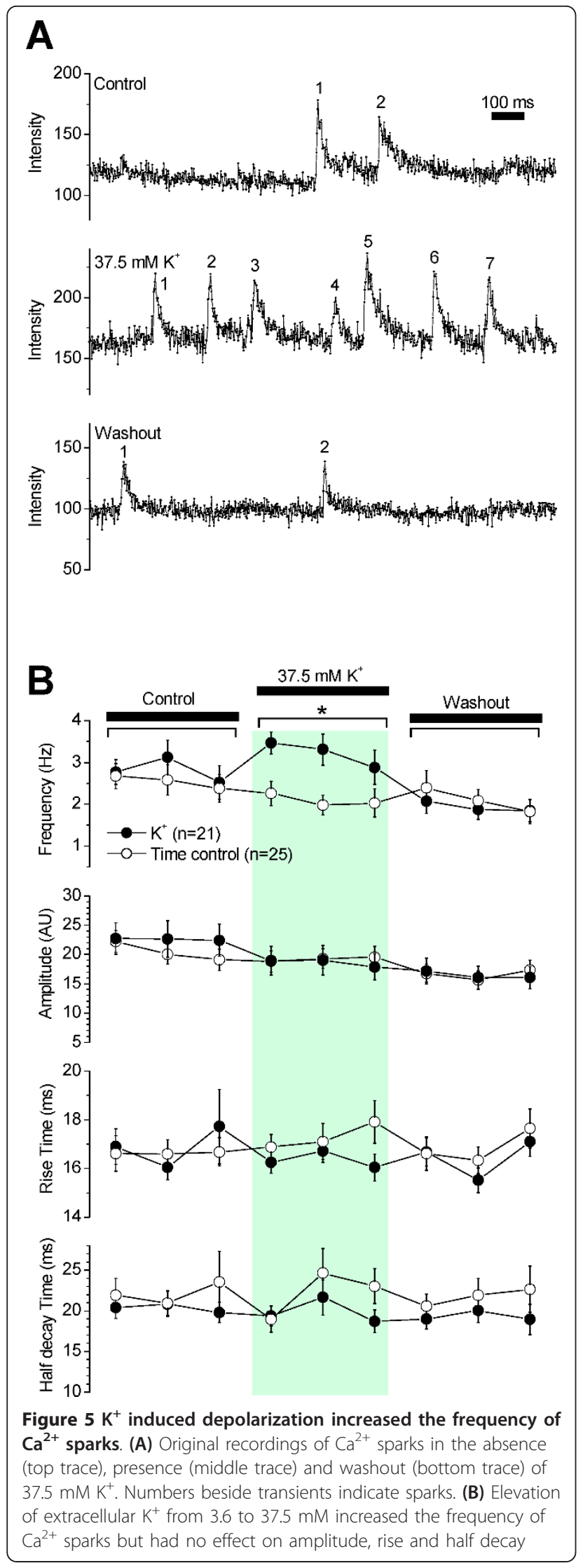

times of $\mathrm{Ca}^{2+}$ sparks. Recordings in the presence of $37.5 \mathrm{mM} \mathrm{K}^{+}$ were made at 10, 40 and $70 \mathrm{~s}$ after $\mathrm{K}^{+}$application and recordings during washout were made at 10,40 and 70s after termination of $\mathrm{K}^{+}$application. Time control experiments are replotted from Figure 3.

$[8,15,16]$, portal vein [17], urinary bladder [11,18], airways $[19,20]$ and retinal arterioles [21]. Interestingly, ryanodine-dependent $\mathrm{Ca}^{2+}$ sparks were detected in smooth muscle cells of cremaster feed arteries but not in cremaster arterioles [22]. In this context, the observation of robust ryanodine-sensitive $\mathrm{Ca}^{2+}$ sparks in the smooth muscle cells of the intact SMA, a small-caliber third order branch of the basilar artery, is an important observation (Figure 2).

The gerbil SMA was found to generate well-defined sparks at robust frequencies. $\mathrm{Ca}^{2+}$ sparks occurred at individual spark sites with an average frequency of $2.6 \pm$ $0.1 \mathrm{~Hz}$ (Figure 2). This frequency is higher than what has been reported for isolated smooth muscle cells $[8,11,15,17,18,20,23]$ as well as intact cerebral arteries [13] and pressurized mesenteric arteries [16]. Rise time was $\sim 17 \mathrm{~ms}$, which is roughly similar to the rise time of $20 \mathrm{~ms}$ reported for rat cerebral vessels [8,24]. Time to half decay was $\sim 21 \mathrm{~ms}$, which is slightly faster than the $27 \mathrm{~ms}$ reported for rat portal vein $[17,19]$ and much faster than $48-65 \mathrm{~ms}$ reported in cerebral vessels $[8,24,25]$. In fact, time to half decay of $\mathrm{Ca}^{2+}$ sparks in the gerbil SMA was more similar to the $23-37 \mathrm{~ms}$ reported for rat heart $[26,27]$. Reasons for these differences may be due to species differences, due to individuality among blood vessels and differences in experimental conditions.

$\mathrm{Ca}^{2+}$ sparks are regulated by intracellular $\mathrm{Ca}^{2+}[4]$. In smooth muscle cells, intracellular $\mathrm{Ca}^{2+}$ is strictly regulated by membrane potential. Membrane depolarization by electrical or chemical means or graded increases in intraluminal pressure increases intracellular $\mathrm{Ca}^{2+}$ via $\mathrm{Ca}^{2+}$ influx and $\mathrm{Ca}^{2+}$ release $[13,28,29]$. Membrane depolarization induced by elevation of $\mathrm{K}^{+}$has been previously shown to induce vasoconstriction of the SMA, which is sensitive to block of L-type VDCCs [30]. The observation that elevation of $\mathrm{K}^{+}$increased $\mathrm{Ca}^{2+}$ spark frequency (Figure 5) suggests that $\mathrm{Ca}^{2+}$ sparks play a role in the regulation of smooth muscle excitability and contractility.

In summary, the data presented here establish the intact spiral modiolar artery as an excellent model for the study of RyR-mediated $\mathrm{Ca}^{2+}$ signaling in smooth muscle cells of small arteries $(<70 \mu \mathrm{m})$ since it generates high amplitude $\mathrm{Ca}^{2+}$ sparks at robust frequencies. The data suggest a role for $\mathrm{Ca}^{2+}$ sparks in regulating vascular tone of the SMA and cochlear blood flow. 


\section{Methods}

Animal use

Female gerbils (2 - 3 months old) were anesthetized with sodium pentobarbital (100 mg/kg i.p.) and sacrificed by decapitation. All procedures concerning animals were performed under a protocol approved by the Institutional Animal Care and Use Committee at Kansas State University. Temporal bones housing the cochleae were removed, opened, and placed in a chilled (at $4^{\circ} \mathrm{C}$ ) physiological salt solution. The spiral modiolar artery (SMA) is a long vessel (about 7-9 $\mathrm{mm}$ in the gerbil) that surrounds and remains loosely coiled against the eighth cranial nerve in the modiolus of the cochlea. The SMA was gently separated from the surrounding nerve and uncoiled taking care not to stretch the artery. Vessels segments were obtained from the center portion of the vessel, avoiding edges that may have been damaged during isolation.

\section{Bodipy staining}

Isolated vessel segments were incubated for $1 \mathrm{hr}$ at RT in PSS containing $0.2 \%$ Triton-X and $1 \mu \mathrm{M}$ Bodipy ${ }^{\circledR}$-ryanodine (Molecular Probes, Eugene OR) with or without $250 \mu \mathrm{M}$ unlabelled ryanodine. Vessels segments were washed, mounted on slides and observed by confocal microscopy (LSM-510Meta, Carl Zeiss, Germany).

\section{Vascular superfusion}

Isolated vessel segments were mounted on a custom-built superfusion chamber and held with two blunt glass needles operated by joy-stick micromanipulators (MN-151, Narashige, Japan). The bath chamber was installed on the stage of an inverted microscope. Superfusion was set to a rate of 2.5 bath chamber volumes per second. Water jacketing of perfusion lines ensured a constant temperature of $37^{\circ} \mathrm{C}$ and minimized the formation of air bubbles, which pose a threat to the vessel segment. Vessels were superfused either with a physiological saline solution (PSS) containing (in $\mathrm{mM}$ ) $150 \mathrm{NaCl}, 3.6 \mathrm{KCl}, 1 \mathrm{MgCl}_{2}, 1 \mathrm{CaCl}_{2}$, 5 HEPES, and 5 glucose, $\mathrm{pH} 7.4$ or with a $37.5 \mathrm{mM} \mathrm{K}^{+}$ solution containing $115 \mathrm{NaCl}, 37.5 \mathrm{KCl}, 1 \mathrm{MgCl}_{2}, 1 \mathrm{CaCl}_{2}$, 5 HEPES and 5 glucose, $\mathrm{pH}$ 7.4. Caffeine was directly dissolved in PSS and ryanodine was solubilized in DMSO before introduction into PSS. The final DMSO concentration was $0.1 \%$. Drugs were purchased from Sigma-Aldrich (St. Louis, MO).

\section{Measurement of $\mathrm{Ca}^{2+}$ Sparks}

Isolated vessel segments were loaded with the $\mathrm{Ca}^{2+}$ indicator dye fluo-4 AM $(5 \mu \mathrm{M}$, Molecular Probes, Eugene, $\mathrm{OR}$ ) for 40 minutes at $37^{\circ} \mathrm{C}$ and mounted in a superfusion chamber fixed on the motorized stage of an inverted microscope (Axiovert 200, Carl Zeiss, Göttingen,
Germany). The $\mathrm{Ca}^{2+}$ indicator dye fluo-4 is an analog of the commonly used fluo-3 that provides higher signal levels in response to excitation with the $488 \mathrm{~nm}$ line of the argon laser (Molecular Probes Product Information Sheet). Superfusion was carried out as described above. Fluo- 4 was excited by the argon laser $(488 \mathrm{~nm})$ operated at $9 \mathrm{~mW}(30 \%$ of the maximum power of $30 \mathrm{~mW})$ that was attenuated by an acousto-optical tunable filter to $1 \%$ for the measurement of $\mathrm{Ca}^{2+}$ sparks (LSM-Meta, Carl Zeiss, Göttingen, Germany). The beam path consisted of a notch filter $(488 \mathrm{~nm})$ followed by two long-pass filters (490 and $505 \mathrm{~nm}$ ) and an oil immersion objective (PlanNeofluar 40x, 1.3 NA, Carl Zeiss). $\mathrm{Ca}^{2+}$ sparks were imaged in confocal xy scans $(76.8 \times 5.2 \mu \mathrm{m}$ corresponding to $512 \times 35$ pixels) with a spatial $(\mathrm{x}, \mathrm{y}, \mathrm{z})$ resolution of $0.15 \times 0.15 \mu \mathrm{m}$ spatial resolution, an optical depth $<0.9$ $\mu \mathrm{m}$ and a temporal resolution of $41.5 \mathrm{~ms}$ (Figure 2A). For detailed analysis of spark kinetics, $\mathrm{Ca}^{2+}$ sparks were recorded in 5s non-confocal (open pinhole) line scans. Line scans, defined as repeated sweeps of the scanner along a single line $(76.8 \mu \mathrm{m}$ corresponding to 512 pixels), were performed at a chosen spark site with a spatial $(\mathrm{x}, \mathrm{z})$ resolution of $0.15 \times<12.4 \mu \mathrm{m}$ and a temporal resolution of $1.92 \mathrm{~ms}$. Nine consecutive line scans, each lasting $5 \mathrm{~s}$, were taken. The time interval between line scans was $\sim 40 \mathrm{~s}$ between the first and the second scan and $\sim 25 \mathrm{~s}$ between all further scans.

\section{$\mathrm{Ca}^{2+}$ spark detection and analysis}

Line scan images $(512 \times 2605$ pixels $)$, covering $76.8 \mu \mathrm{m}$ for $5 \mathrm{~s}$, were visually inspected for sparks. Intensity values covering the width of a spark site were averaged and exported to a text file ('raw data') for analysis using an algorithm written in Labtalk (Origin 6.0, OriginLab). Frequency, amplitude, rise time $(0-100 \%)$ and time to half-decay were determined for individual spark sites (Figure 2).

The analysis algorithm used the 'raw' data as well as a 'subtracted' data set that was generated by subtraction of a 'baseline' dataset generated by a 601-point sliding window average from a 'smoothed' dataset generated by a 5 point sliding window average of the 'raw' data. The 'subtracted' data were used for the identification of $\mathrm{Ca}^{2+}$ sparks. Sparks were identified by a user-defined number of consecutive intensity increases that spanned a userdefined minimum amplitude. 'Subtracted' data were further used to evaluate whether a spark is suitable for determining amplitude, rise and decay times. Suitable sparks are sparks that arise near or below the baseline (Figure 2C). Sparks that follow a previous spark too closely arise from a higher value which could lead to an underestimate of their amplitude (Figure 2D). Amplitude was determined as difference between the raw data peak 
and the base of the spark. The base was determined as the average of 10 raw data points immediately prior to the first of the consecutive increases. The rise time was the time from the end of the base to the peak and the time to half decay was the time between the peak and the time when the 'averaged' data decayed by half of the amplitude. The 'raw' data were graphed and annotated for visual inspection (Figure 2). Each identified spark was marked by a number and by a vertical indicator line transecting the peak of the spark. Measurable sparks received additional annotation including a horizontal line segment marking the base of the spark and a vertical line transecting the time of half decay. Measurements of amplitude, rise time and time to half-decay were averages of data that passed visual inspection.

\section{Statistics}

Frequency, amplitude, rise and half-decay times of $\mathrm{Ca}^{2+}$ sparks were graphed as averages of values during each of the nine sequential measurements. $\mathrm{Ca}^{2+}$ spark data reported in the text are averages of three sequential measurements. Error bars are SEM. Significance was assumed at $p<0.05$ and determined by either paired or unpaired t-test, as appropriate.

\section{Acknowledgements}

The support by NIH R01 DC04280 is gratefully acknowledged. A major portion of this study has been submitted by Keil Regehr in partial fulfillment of the requirements for the degree of Master of Science in Electrical Engineering and Computer Science at Kansas State University.

\section{Author details}

${ }^{1}$ Anatomy \& Physiology Department, Kansas State University, Manhattan, Kansas 66506, USA. ENT-Department, Technical University of Munich, Munich, Germany. ${ }^{3}$ Department of Biomedical Engineering, University of Wisconsin-Madison, Madison, WI, USA.

\section{Authors' contributions}

GK, KR, EQS and PW wrote the manuscript. KR collected and analyzed $\mathrm{Ca}^{2+}$ sparks data, developed the software code for sparks analysis. SB performed the Bodipy-ryanodine staining. PW conceived of the study and participated in the design of experiments and development of the analysis software. All authors have read and agreed to the final version of the manuscript.

Received: 15 June 2011 Accepted: 26 August 2011

Published: 26 August 2011

\section{References}

1. Axelsson A: Comparative anatomy of cochlear blood vessels. Am J Otolaryngol 1988, 9:278-290.

2. Wangemann P, Liu J, Marcus DC: Ion transport mechanisms responsible for $\mathrm{K}+$ secretion and the transepithelial voltage across marginal cells of stria vascularis in vitro. Hear Res 1995, 84:19-29.

3. Davis MJ, Hill MA: Signaling mechanisms underlying the vascular myogenic response. Physiol Rev 1999, 79:387-423.

4. Cheng H, Lederer WJ: Calcium sparks. Physiol Rev 2008, 88:1491-1545.

5. Knot HJ, Standen NB, Nelson MT: Ryanodine receptors regulate arterial diameter and wall $[\mathrm{Ca} 2+]$ in cerebral arteries of rat via Ca2+-dependent K+ channels. J Physiol 1998, 508(Pt 1):211-221.

6. Bolton TB, Imaizumi Y: Spontaneous transient outward currents in smooth muscle cells. Cell Calcium 1996, 20:141-152.
7. Jaggar JH, Wellman GC, Heppner TJ, Porter VA, Perez GJ, Gollasch M, Kleppisch T, Rubart M, Stevenson AS, Lederer WJ, et al: Ca2+ channels, ryanodine receptors and $\mathrm{Ca}(2+)$-activated $\mathrm{K}+$ channels: a functional unit for regulating arterial tone. Acta Physiol Scand 1998, 164:577-587.

8. Nelson MT, Cheng H, Rubart M, Santana LF, Bonev AD, Knot HJ, Lederer WJ: Relaxation of arterial smooth muscle by calcium sparks. Science 1995, 270:633-637.

9. Wonneberger K, Scofield MA, Wangemann P: Evidence for a calciumsensing receptor in the vascular smooth muscle cells of the spiral modiolar artery. J Membr Biol 2000, 175:203-212.

10. Li L, Ma KT, Zhao L, Si JQ: Niflumic acid hyperpolarizes the smooth muscle cells by opening $\mathrm{BK}(\mathrm{Ca})$ channels through ryanodine-sensitive $\mathrm{Ca}$ (2+) release in spiral modiolar artery. Sheng Li Xue Bao 2008, 60:743-750.

11. Collier ML, Ji G, Wang Y, Kotlikoff Ml: Calcium-induced calcium release in smooth muscle: loose coupling between the action potential and calcium release. J Gen Physiol 2000, 115:653-662.

12. Jaggar JH, Porter VA, Lederer WJ, Nelson MT: Calcium sparks in smooth muscle. Am J Physiol Cell Physiol 2000, 278:C235-C256.

13. Jaggar $\mathrm{HH}$, Stevenson AS, Nelson MT: Voltage dependence of $\mathrm{Ca} 2+$ sparks in intact cerebral arteries. Am J Physiol 1998, 274:C1755-C1761.

14. Wangemann P, Cohn ES, Gruber DD, Gratton MA: Ca2+-dependence and nifedipine-sensitivity of vascular tone and contractility in the isolated superfused spiral modiolar artery in vitro. Hear Res 1998, 118:90-100.

15. Furstenau M, Lohn M, Ried C, Luft FC, Haller H, Gollasch M: Calcium sparks in human coronary artery smooth muscle cells resolved by confocal imaging. J Hypertens 2000, 18:1215-1222.

16. Miriel VA, Mauban JR, Blaustein MP, Wier WG: Local and cellular Ca2+ transients in smooth muscle of pressurized rat resistance arteries during myogenic and agonist stimulation. J Physiol 1999, 518(Pt 3):815-824.

17. Gordienko DV, Bolton TB: Crosstalk between ryanodine receptors and IP (3) receptors as a factor shaping spontaneous $\mathrm{Ca}(2+)$-release events in rabbit portal vein myocytes. J Physiol 2002, 542:743-762.

18. Herrera GM, Heppner TJ, Nelson MT: Voltage dependence of the coupling of $\mathrm{Ca}(2+)$ sparks to $\mathrm{BK}(\mathrm{Ca})$ channels in urinary bladder smooth muscle. Am J Physiol Cell Physiol 2001, 280:C481-C490.

19. Mironneau J, Arnaudeau S, Macrez-Lepretre N, Boittin FX: Ca2+ sparks and $\mathrm{Ca} 2+$ waves activate different $\mathrm{Ca}(2+)$-dependent ion channels in single myocytes from rat portal vein. Cell Calcium 1996, 20:153-160.

20. Liu QH, Zheng YM, Wang YX: Two distinct signaling pathways for regulation of spontaneous local Ca2+ release by phospholipase $C$ in airway smooth muscle cells. Pflugers Arch 2007, 453:531-541.

21. Curtis TM, Tumelty J, Dawicki J, Scholfield CN, McGeown JG: Identification and spatiotemporal characterization of spontaneous Ca2+ sparks and global Ca2+ oscillations in retinal arteriolar smooth muscle cells. Invest Ophthalmol Vis Sci 2004, 45:4409-4414.

22. Westcott EB, Jackson WF: Heterogeneous function of ryanodine receptors, but not IP3 receptors, in hamster cremaster muscle feed arteries and arterioles. Am J Physiol Heart Circ Physiol 2011, 300:H1616-H1630.

23. Gordienko DV, Bolton TB, Cannell MB: Variability in spontaneous subcellular calcium release in guinea-pig ileum smooth muscle cells. J Physiol 1998, 507(Pt 3):707-720.

24. Perez GJ, Bonev AD, Patlak JB, Nelson MT: Functional coupling of ryanodine receptors to KCa channels in smooth muscle cells from rat cerebral arteries. J Gen Physiol 1999, 113:229-238.

25. Bonev $A D$, Jaggar $J H$, Rubart M, Nelson MT: Activators of protein kinase $C$ decrease $\mathrm{Ca} 2+$ spark frequency in smooth muscle cells from cerebral arteries. Am J Physiol 1997, 273:C2090-C2095.

26. Cheng H, Lederer WJ, Cannell MB: Calcium sparks: elementary events underlying excitation-contraction coupling in heart muscle. Science 1993, 262:740-744.

27. Lukyanenko V, Gyorke I, Gyorke S: Regulation of calcium release by calcium inside the sarcoplasmic reticulum in ventricular myocytes. Pflugers Arch 1996, 432:1047-1054.

28. Knot HJ, Nelson MT: Regulation of arterial diameter and wall [Ca2+] in cerebral arteries of rat by membrane potential and intravascular pressure. J Physiol 1998, 508(Pt 1):199-209.

29. Kamishima T, McCarron JG: Regulation of the cytosolic Ca2+ concentration by $\mathrm{Ca} 2+$ stores in single smooth muscle cells from rat cerebral arteries. J Physiol 1997, 501(Pt 3):497-508. 
30. Wangemann P, Gruber DD: The isolated in vitro perfused spiral modiolar artery: pressure dependence of vasoconstriction. Hear Res 1998 115:113-118

doi:10.1186/1472-6793-11-15

Cite this article as: Krishnamoorthy et al:: Calcium sparks in the intact gerbil spiral modiolar artery. BMC Physiology 2011 11:15.

Submit your next manuscript to BioMed Central and take full advantage of:

- Convenient online submission

- Thorough peer review

- No space constraints or color figure charges

- Immediate publication on acceptance

- Inclusion in PubMed, CAS, Scopus and Google Scholar

- Research which is freely available for redistribution 